\title{
Mothers Living With Contamination Of Perfluoroalkyl Substances: An Assessment Of The Perceived Health Risk And Self-Reported Diseases
}

\author{
Paolo Girardi ( $\sim$ paolo.girardi@unive.it ) \\ Ca' Foscari University of Venice: Universita Ca' Foscari https://orcid.org/0000-0001-8330-9414 \\ Alice Lupo \\ Università degli Studi di Padova: Universita degli Studi di Padova \\ Libera Ylenia Mastromatteo \\ University of Padova: Universita degli Studi di Padova \\ Sara Scrimin \\ University of Padova: Universita degli Studi di Padova
}

\section{Research Article}

Keywords: Perfluoroalkyl substances, cross-sectional study, breastfeeding, health outcomes, risk perception.

Posted Date: March 7th, 2022

DOI: https://doi.org/10.21203/rs.3.rs-1323585/v1

License: @ (1) This work is licensed under a Creative Commons Attribution 4.0 International License. Read Full License 


\section{Abstract}

Widespread contamination of the superficial, drinking, and groundwater by perfluoroalkyl substances (PFAS) was discovered in the Veneto Region (northeast of Italy) in 2013. Mothers from the contaminated area were concerned about the effects of PFAS on their own and their children's health. We determined the factors that influenced the perceived risk of PFAS and the presence of self-reported diseases by conducting a study with 384 mothers of children aged 1-13 years living in the contaminated area (Red Zone, Veneto, Italy). Information on demography, the sources of exposure, and the health condition of the mothers was collected through an online survey. The serum PFAS concentration was recorded for some of the participants. We determined the factors influencing the perceived risk, risk of health outcomes, and serum PFAS levels through regression analyses. The PFAS perceived risk of the mothers increased with an increase in the trust in scientific institutions and social media, and when many friends were present, trust in politics and full-time employment had a protective effect. The PFAS perceived risk increased the occurrences of self-reported and autoimmune diseases. Longer residence (>20 years) in the most exposed area (Red Zone A) increased the frequency of some health outcomes. Serum PFAS concentrations decreased with breastfeeding, but increased with tap water consumption, residence in Red Zone A, and residence time. The PFAS perceived risk of the mothers was associated with many factors that influenced reporting of health issues. The association between PFAS exposure and health outcomes needs further investigation.

\section{Introduction}

Perfluoroalkyl substances (PFAS) are industrial compounds characterized by a fluorinated carbon chain that is attached to a functional end group. Because of their hydrophobic and lipophobic properties, they are used in various products, such as non-stick cookware and water-repellent products (Buck et al., 2011). They tend to bioaccumulate and persist in the environment and the body (Conder et al., 2008; Perez et al., 2013).

One of the first incidences of contamination was discovered in the Mid-Ohio Valley (United States), where PFAS released from a fluoropolymer-producing plant contaminated surface water and groundwater, which affected 70,000 people (Emmett et al., 2006; Frisbee et al., 2009). Similarly, in 2013, a factory, based in the Veneto Region in Italy (RIMAR-MITENI factory, Trissino, Vicenza province), active since the late 1960s, contaminated one of the largest underground aquifers in Europe (Girardi \& Merler, 2019; Lava et al., 2021). The residents were inadvertently exposed to PFAS for a long time through drinking water, which resulted in high serum PFAS levels (Domingo \& Nadal, 2019; Pitter et al., 2020). Besides drinking water, other factors that affected the health of individuals were gender, the duration of residence in the zone, and raising livestock (Ingelido et al., 2018; Pitter et al., 2020).

Many health problems are associated with PFAS exposure. The C8 panel, a working group that investigated the effects of PFAS contamination in the Mid-Ohio Valley, reported a "probable link" between PFAS exposure and some types of cancer, specifically, kidney and testicular cancer (Steenland \& Winquist, 2021), and a strong association with other health diseases, such as ulcerative colitis, pregnancy-induced hypertension, hypercholesterolemia, and liver diseases (Steenland et al., 2020). Other research groups confirmed these associations of PFAS exposure with dyslipidemia (Sunderland et al., 2019; Averina et al., 2021), kidney functionality (Blake et al., 2018), hypertension (Averina et al., 2021), and liver diseases (Girardi and Merler, 2019; Costello et al., 2021). Additionally, PFAS exposure was associated with several effects during pregnancy, especially preeclampsia (Borghese et al., 2020; Bommarito et al., 2021) and glucose tolerance (Preston et al., 2020). The effects of PFAS can also occur in the unborn child because PFAS can cross the placental barrier during pregnancy. Thus, pregnant women represent an important subpopulation affected by PFAS contamination (ManzanoSalgado et al., 2015). The amount of PFAS in the blood of the pregnant mothers is negatively associated with the birth weight and/or head circumference of infants (Apelberg, et al., 2007), as well as, with a weak immune system in children (Grandjean et al., 2012) and a higher risk of birth defects (Stein et al., 2014). Furthermore, high PFAS levels in the mother's blood were documented to interfere with the sexual development of male infants, potentially leading to infertility (Di Nisio et al., 2020). These substances pass from the mother to the child in the uterus and through breast milk. Hence, nursing by mothers with high PFAS levels is an additional and lasting source of contamination during early childhood (Fromme et al., 2010). Breastfeeding lowers maternal serum concentration of PFOA (-3\% per month of breastfeeding; $95 \% \mathrm{Cl}:-5 \%--2 \%$ ) and increases infant serum PFOA concentrations (6\% per month of breastfeeding; $95 \% \mathrm{Cl}$ : 1-10\%; Mondal et al., 2014). Therefore, prolonged breastfeeding could decrease maternal serum PFAS concentration but increase PFAS concentration in infants (Kim et al., 2020), resulting in toddlers with higher total PFAS blood concentrations than their mothers (Papadopoulou et al., 2016). Furthermore, parous women have $40 \%$ lower PFOA (95\% Cl: $-54 \%--23 \%)$, colostrum concentration (Jusko et al., 2016), and 70\% lower PFOA plasma concentration, compared to nulliparous women (Brantsæter et al., 2013); previous pregnancies probably contribute to the elimination of PFAS in lactating mothers (Manzano-Salgado et al., 2016). The effect of breastfeeding on PFAS 
levels in infants is particularly relevant as it is strongly recommended worldwide to breastfeed infants for the first six months after childbirth for their optimal growth (WHO, 2002).

Although several studies have shown an association between PFAS and health risks, the information shared with the general population has been poor, which has led to confusion (Wickham \& Shriver, 2021). Therefore, the PFAS-exposed community, overall, ignored and/or did not fully understand the effects of such exposure, which increased the state of uncertainty regarding the impacts of the contamination on their health and socioeconomic condition (Banwell et al., 2021; Calloway et al., 2020). Uncertainty when facing potential threats increases stress and anxiety (Sapolsky, 2000), which can influence the perception of health problems. Among mothers, the level of perceived stress can increase due to the fear of having exposed their offspring to environmental risks, the worry of being unable to protect them, and feeling guilt for possibly being the direct source of contamination (through the placenta and breastfeeding) (Crighton et al., 2012).

In this study, we assessed mothers living in a Region of Italy with high PFAS contamination. The data were derived from a pilot study known as the TEDDY-Child (Tracing the Environmental Determinants of the Development of Your Child) study that investigated the potential effects of PFAS-exposure on multiple domains related to the development of children.

The perceived risk of the mothers due to PFAS exposure, the self-reported health outcomes, and the real determinants of high serum blood PFAS levels were jointly analyzed along with three separate but related research questions (RQs):

- RQ1: What environmental and subjective factors influence the risk perception of mothers regarding PFAS contamination?

- RQ2: Do environmental factors that are linked to PFAS exposure and risk perception influence the occurrences of self-reported diseases?

- RQ3: What environmental and individual factors are the best predictors of serum blood PFAS levels?

The theoretical simplified network of relationships between and within the RQs and influencing variables is represented in Fig. 1 by means of a Directed Acyclic Graph (DAG). The aim of this study was to explore each research question among a subpopulation of mothers of young children living in a territory affected by a severe PFAS contamination.

[ insert Fig. 1 here ]

\section{Methods}

\section{Study Population}

The sample was derived from the TEDDY-Child study (Tracing the Environmental Determinants of the Development of Your Child) that was conducted by the University of Padua to investigate the effects of PFAS on the development of children in the Veneto Region (Italy). From March to June 2021, 384 participants (mothers) were recruited from families that lived in contaminated areas in Veneto, called the "Red Zone" (Pitter et al., 2020). This is a territory comprising the province of Padua, Vicenza, and Verona formed by 30 municipalities. The population here was exposed to PFAS via contaminated drinking water for several decades. The regional Health Service subdivided the 30 municipalities into two areas based on the different intensities of PFAS contamination, namely, Red Zone A and Red Zone B, depending on whether the municipality was located above the contaminated region of the underground aquifer (Pitter et al., 2020). The recruitment was voluntary, and all participants provided informed consent. The study was approved by the ethical committee of the researchers' university (Protocol number 4051). Data used in this analysis were derived from two subsequent ad-hoc questionnaires provided to the participants to determine the sociodemographic characteristics and lifestyle of the mothers and their children; detailed information of the children 1-13 years old (born after 2008) was collected.

\section{Blood PFAS measures}

A health surveillance program was launched in January 2017 as a free population-based screening program offered by the regional Health Service for the residents of the Red Zone. PFAS were quantified using high-performance liquid chromatography-tandem mass spectrometry (HPLC-MS/MS) [Prominence UFLC XR 20 (Shimadzu) coupled to an API 4000TM LC-MS/MS System (Sciex)] that included perfluorooctanesulfonate (PFOS), perfluorooctanoic acid (PFOA), perfluorohexanesulfonic acid (PFHxS), perfluorononanoic acid (PFNA), perfluoroheptanoic acid (PFHpA), perfluorobutanesulfonic acid (PFBS), perfluorohexanoic acid (PFHxA), perfluorobutanoic acid (PFBA), perfluoropentanoic acid (PFPeA), perfluorodecanoic acid (PFDeA), perfluoroundecanoic acid (PFUnA), and perfluorododecanoic acid (PFDoA). Additional information on the analytical method is published in another study (Pitter et al., 2020). Out of the 384 participants, 
148 reported their serum concentrations for 12 types of PFAS. The analysis was performed for $2017-2020$ (82.8\% in 2018). Three types of PFAS, including PFOA, PFOS, and PFHxS, were considered for the subsequent analysis. Out of 148 measurements, three measurements of PFHxS and two of PFOS were missing, while the remaining measurements were higher than the limit of quantification (LOQ) equal to $0.5 \mathrm{ng} / \mathrm{mL}$.

\section{Self-reported health outcome}

The participants were asked to report the presence of pathologies or diseases. The question was in an open-text format, and the response was decoded by extracting the presence of autoimmune diseases (thyroid problems, celiac disease, lower immune functioning, Crohn's disease, Type 1 and Type 2 diabetes, lupus, rheumatoid arthritis, and psoriasis), cardiovascular diseases (high cholesterol, high blood pressure, stroke, cardiomyopathy, left atrial myxoma, high triglycerides, atrial fibrillation, ventricular tachycardia, and heart palpitations), liver diseases (increased liver enzymes, altered liver functioning, and cholecystitis), cancer (any benign or malignant tumor), and complications during pregnancy (preeclampsia, gestational diabetes, and preterm delivery).

\section{Descriptive statistical analysis}

The variables were summarized in tables and figures (frequency for categorical variables, median and Interquartile Range (IQR) for continuous variables). Wilcoxon test was performed to compare the distribution of continuous variables between the two Red Zones (A and $B)$ and by binary categorization of blood PFOA concentrations according to the median value $(17 \mathrm{ng} / \mathrm{mL})$. The relationship between categorical variables was tested using chi-squared tests. The differences among and between groups were considered to be statistically significant at $p<0.05$.

\section{Missing data imputation}

To fill the missing values for the records of some participants, we used the Multivariate Imputation by Chained Equations (MICE) algorithm (Van Buuren, 2011), under the Missing at Random (MAR) assumption. From the 384 participants, only some data were missing; the variables with the relative percentage of missing data were tap water usage $(0.52 \%)$, meat consumption $(0.26 \%)$, vegetable consumption $(0.26 \%)$, number of children $(0.26 \%)$, body mass index $(0.52 \%)$, education level $0.52 \%)$, employment $(0.26 \%)$, type of house $(0.52 \%)$, perceived risk of PFAS $(0.52 \%)$, health outcomes $(3.90 \%)$, trust in scientific institutions $(0.26 \%)$, trust in political institutions (2.08\%), trust in social media (1.82\%), and Multidimensional Scale of Perceived Social Support (MSPSS; Zimet et al., 1988) by friends $(0.78 \%)$. The imputation process was performed by predictive mean matching for the continuous distribution of the variables, except for dichotomous variables where a binary logistic regression was performed. The imputation algorithm was iterated 30 times and the convergence was graphically evaluated to inspect the variability of the imputed values.

\section{RQ1: Cumulative Logistic Model - factors influencing risk perception}

We evaluated the PFAS perceived health risk on a 10-point Likert scale and asked the respondents, "To what extent do you think PFAS can affect your health and physical well-being?" We used a cumulative logistic model to evaluate which factors influenced the level of the perceived risk of PFAS. We included variables for the trust in scientific institutions (10-point Likert), political institutions (10-point Likert), and social media (10-point Likert). Additionally, individual predictors, such as the mother's age ( $\leq 38,38-44,>44$ years), the education level (middle school, high school, degree, or higher), residence time ( $\leq 20$ years or $>20$ years), the employment status of the mother (housewife/unemployed, part-time, full-time), PFAS measurement (Absent, Present-PFOA [ $\leq 17 \mathrm{ng} / \mathrm{mL}]$, Present-PFOA [>17 ng/mL]), residence in the Red Zone (A or B), tap water consumption (10-point Likert scale), and the number of children, were considered. Only those variables were selected that minimized the Akaike Information Criterion (AIC) in a backward approach. Since low values of risk perception were infrequent, we merged the values of the response variables from 1 to 3 in a unique category $(\leq 3, n=10,2.6 \%)$. The results were reported as Odds Ratios (ORs) through exponentiation of the regression coefficients and relative $95 \%$ Confidence Interval $(95 \% \mathrm{Cl})$. The analysis was performed using the ordinal package in the R software (R-Core Team, 2021).

\section{RQ2: Logistic regression model - assessment of health outcomes}

To determine the factors that might influence the presence of self-reported health issues (any outcomes, including autoimmune diseases, liver diseases, cardiovascular diseases, pregnancy complications), five different logistic regression models were estimated. The selected regressors included PFAS measurements (Absent, Present-PFOA [ $\leq 17 \mathrm{ng} / \mathrm{mL}]$, Present-PFOA [>17 ng/mL]), residence in the Red Zone (A or B), the perceived health risk of PFAS (10-point Likert scale), tap water consumption (10-point Likert scale), and the number of children. The models were also adjusted for the following confounding factors: the mother's age $(\leq 38,38-44,>44$ years), the education level (middle school, high school, university degree, or higher), residence time ( $\leq 20,>20$ years), and the mother's employment status (housewife/unemployed, part-time, or full-time). The results were reported using ORs with the relative $95 \% \mathrm{Cl}$. To avoid excessive reliance 
on statistical significance, we emphasized the strength of associations between parameters by reporting the $95 \% \mathrm{Cl}$ only (Amrhein et al., 2019).

\section{RQ3: Linear regression model - determinants of blood serum PFAS}

Several linear regression models were computed to determine the characteristics that influence the level of each type of PFAS (PFOA, PFOS, and PFHxS). Three separate linear regression models were estimated by type of PFAS, considering the log-transformed PFAS values as dependent variables and the following maternal and pregnancy-related characteristics: age (in years), the education level (middle school or lower, high school, university degree, or higher), the mother's employment status (housewife/unemployed, part-time, or full-time), the number of children before and after 2008, and the number of abortions. Limited to the time window between 2008 and 2021 in the model we included as covariates the following determinants: breastfeeding duration of the first children (no or no yet breastfed, 1-6 months, 6-12 months, 12-24 months, > 24 months), breastfeeding duration of the second children (no or no second child, 1-6 months, 6-12 months, 12-24 months, > 24 months), breastfeeding of the third child had (no or no third child, yes), time since last pregnancy (categorized into 0 or before blood analysis, 0-7 years, $>7$ years). Furthermore, we considered the following maternal lifestyle and characteristics: tap water consumption (10-point Likert scale), meat consumption (local meat, supermarket, butcher's shop, or no consumption), vegetable consumption (local market, own garden, supermarket, or neighboring farms), living in a detached house (no or yes), residence time ( $\leq 20$ years or $>20$ years), and the area of residence at the time of blood collection (Red Zone A or B). All the timerelated variables were rescaled to the date of blood analysis. We performed backward stepwise regression that started with a full model and, at each step, gradually removed variables from the regression model based on the AIC index after testing the presence of interactions between included variables through an $\mathrm{F}$ statistic test. The results were reported using the estimated coefficients and the relative 95\% confidence intervals. We used a Leave-One-Out Cross-Validation (LOOCV) procedure to obtain the Leave-One-Out coefficient of determination $\left(\mathrm{Q}^{2}\right)$ that could be compared to the one from the original linear regression model $\left(\mathrm{R}^{2}\right)$. The regression residual was analyzed to check the overall goodness of the model and for the presence of outliers or influential points.

\section{Results}

The participants were between 24 and 56 years (median: 43 years) with a high education level (40\% of the participants had a university degree or higher educational qualification, and only $7.6 \%$ of the participants had a middle school degree) (Table 1 ). Regarding job employment, mothers were mainly full-time workers (60\%) with lower percentages of homemakers or unemployed individuals (14\%) and part-time employees (26\%). The respondents mainly lived in the Red Zone A (56\%), and $37 \%$ of them were long-term residents ( $\geq 20$ years). The consumption of tap water was low-to-medium (median: 3). Most participants had not undergone PFAS measurements (61\%). The number of children ranged between 1 and 6 (median: 2). The perceived risk of PFAS was high (median: 8, IQR: 7-10). The participants reported high trust in scientific institutions (median: 8, IQR: 7-10) and low confidence in political institutions and social media (both median: 3, IQR: 1-5). Some of the participants (44\%) reported the presence of at least one serious disease and a decreasing frequency of autoimmune diseases (17\%), cardiovascular diseases (5.5\%), liver diseases (3.4\%), and cancer (5.7\%). Many of the participants (23\%) had at least one pregnancy-related complication. With respect to the Red Zone B, the participants who lived in Red Zone A reported significantly higher tap water consumption $(p=0.031)$, number of PFAS measurements $(p<0.001)$, and of children $(p=$ 0.010). Figure 2 shows the extension of the Red Zone in the Veneto Region and the number of mothers participating from each municipality. 
Table 1

The main characteristics of the participants, overall and by zone of residence.

\begin{tabular}{|c|c|c|c|c|}
\hline \multirow[t]{2}{*}{ Characteristics } & \multirow{2}{*}{$\begin{array}{l}\text { Overall, } \\
\mathrm{N}=384^{1}\end{array}$} & \multicolumn{2}{|l|}{ Red Zone* } & \multirow[t]{2}{*}{ P-value $^{2}$} \\
\hline & & $A, N=217^{1}$ & $\mathrm{~B}, \mathrm{~N}=167^{1}$ & \\
\hline Mother's age (years) & & & & 0.87 \\
\hline$[24,38]$ & $136(35 \%)$ & $79(36 \%)$ & $57(34 \%)$ & \\
\hline$(38,44]$ & $124(32 \%)$ & $70(32 \%)$ & $54(32 \%)$ & \\
\hline$(44,56]$ & $124(32 \%)$ & $68(31 \%)$ & $56(34 \%)$ & \\
\hline Educational level & & & & 0.42 \\
\hline Middle school & $29(7.6 \%)$ & $13(6.0 \%)$ & $16(9.6 \%)$ & \\
\hline High school & $201(52 \%)$ & $116(53 \%)$ & $85(51 \%)$ & \\
\hline Degree or higher & $154(40 \%)$ & $88(41 \%)$ & $66(40 \%)$ & \\
\hline Residential time & & & & 0.078 \\
\hline$\leq 20$ years & $242(60 \%)$ & $128(59 \%)$ & $114(60 \%)$ & \\
\hline$>20$ years & $142(37 \%)$ & $89(41 \%)$ & $53(32 \%)$ & \\
\hline Employment & & & & 0.38 \\
\hline Housewife/unemployed & $52(14 \%)$ & $25(12 \%)$ & $27(16 \%)$ & \\
\hline Part-time & $99(26 \%)$ & $59(27 \%)$ & $40(24 \%)$ & \\
\hline Full-time & $233(61 \%)$ & $133(61 \%)$ & $100(60 \%)$ & \\
\hline PFAS measurement & & & & $<0.001$ \\
\hline Absent & $236(61 \%)$ & $119(55 \%)$ & $117(70 \%)$ & \\
\hline Present - [PFOA $\leq 17 \mathrm{ng} / \mathrm{mL}]$ & $74(19 \%)$ & $37(17 \%)$ & $37(22 \%)$ & \\
\hline Present - [PFOA > 17 ng/mL] & $74(19 \%)$ & $61(28 \%)$ & $13(7.8 \%)$ & \\
\hline Tap water habit & $3(1,8)$ & $4(1,9)$ & $3(1,6)$ & 0.031 \\
\hline PFAS perceived health risk & $8(7,10)$ & $8(7,9)$ & $8(7,10)$ & 0.94 \\
\hline MSPSS friends score & $4.25(2.75,6)$ & $4.5(3,6)$ & $4(2.5,6)$ & 0.27 \\
\hline Total N. of children & $2(1,2)$ & $2(2,3)$ & $2(1,2)$ & 0.010 \\
\hline Trust in scientific institutions & $8(7,10)$ & $8(7,10)$ & $8(6,9.5)$ & 0.42 \\
\hline Trust in political institutions & $3(1,5)$ & $3(1,5)$ & $3(1,5)$ & 0.54 \\
\hline Trust in social media & $3(1,5)$ & $3(1,5)$ & $2(1,5)$ & 0.28 \\
\hline Self-reported disease & $168(44 \%)$ & $93(43 \%)$ & $75(45 \%)$ & 0.69 \\
\hline Autoimmune disorders & $66(17 \%)$ & $39(18 \%)$ & $27(16 \%)$ & 0.58 \\
\hline Cardiovascular disorders & $22(5.7 \%)$ & $14(6.5 \%)$ & $8(4.8 \%)$ & 0.58 \\
\hline Liver diseases & $14(3.6 \%)$ & $10(4.6 \%)$ & $4(2.4 \%)$ & 0.25 \\
\hline Cancer & $22(5.7 \%)$ & $12(5.5 \%)$ & $10(6.0 \%)$ & 0.85 \\
\hline Pregnancy complications & $88(23 \%)$ & $50(23 \%)$ & $38(23 \%)$ & 0.95 \\
\hline${ }^{7}$ Median (IQR) or Frequency & & & & \\
\hline
\end{tabular}


[ insert Table 1 here ]

[ insert Fig. 2 here]

Perceived health risk due to PFAS

The result of the cumulative logistic regression is reported in Table 2. The participants who reported a higher perceived health risk due to PFAS also reported high trust in scientific institutions (1 point increase OR: $1.15 ; 95 \% \mathrm{Cl}$ : $1.05-1.26)$ and social media (1 point increase OR: $1.11 ; 95 \% \mathrm{Cl}: 1.01-1.22)$, whereas, trust in political institutions had a protective effect (1 point increase OR: $0.83 ; 95 \%$ Cl: $0.76-0.92$ ). Participants with full-time employment were less worried about the health risk due to PFAS exposure than a housewife or an unemployed individual (OR: $0.54 ; 95 \% \mathrm{Cl}: 0.31-0.93)$. The social support of friends was associated with a higher perceived risk of PFAS (1 point increase OR: 1.13; $95 \% \mathrm{Cl}: 1.03-1.25)$.

Table 2

The ORs and the $95 \% \mathrm{Cl}$ estimated by a cumulative logistic regression model with the perceived health risk of PFAS as the dependent variable.

[ insert Table 2 here ]

\begin{tabular}{|llll|}
\hline Predictors & OR & $95 \% \mathrm{Cl}$ & $\boldsymbol{P}$-values \\
\hline Trust in scientific institutions [+ 1 pt.] & 1.15 & $1.05-1.26$ & $\mathbf{0 . 0 0 4}$ \\
\hline Trust in political institutions [+ 1 pt.] & 0.83 & $0.76-0.92$ & $<\mathbf{0 . 0 0 1}$ \\
\hline Trust in social media [+ 1 pt.] & 1.11 & $1.01-1.22$ & $\mathbf{0 . 0 3 7}$ \\
\hline Housewife/unemployed (reference) & 1.00 & - & - \\
\hline Part-time & 0.70 & $0.38-1.29$ & 0.253 \\
\hline Full-time & 0.54 & $0.31-0.93$ & $\mathbf{0 . 0 2 8}$ \\
\hline MSPSS friends score [+ 1 pt.] & 1.13 & $1.03-1.25$ & $\mathbf{0 . 0 1 1}$ \\
\hline
\end{tabular}

Health outcomes

Mothers living in the Red Zone for a long time did not report an increase in the frequency of diseases, except for cancer ( $>20$ years: OR: $2.15,95 \% \mathrm{Cl}$ : 0.80-5.92). Mothers living in Red Zone A reported risk effects of cardiovascular and liver diseases with respect to those in the Red Zone B (OR: 1.63; $95 \% \mathrm{Cl}$ : 0.60-9.81, and OR: 2.28; 95\% Cl: $0.61-9.81$, respectively). One point increase in the consumption of tap water was associated with a relative increase in the probability to report an increase of $7 \%$ in any self-reported disease (95\% Cl: $1-$ 14\%), $21 \%$ cancer (95\% Cl: 6-40\%), 6\% pregnancy complication (95\% Cl: $-1-14 \%)$, and 5\% autoimmune disorders (95\% $\mathrm{Cl}$ : $-3-13 \%)$.

When PFOA was present, the reporting of any self-reported disease was higher (OR: 1.73, 95\% Cl: 1.01-3.00 and OR: 1.40, 95\% Cl: 0.782.52 for PFOA levels below and above $17 \mathrm{ng} / \mathrm{mL}$, respectively). Additionally, the PFAS perceived risk was associated with an increase in the occurrence of self-reported diseases (+14\% for each 1 point increase; $95 \% \mathrm{Cl}: 2-28 \%)$ and autoimmune diseases $(+19 \%$ for each 1 point increase; $95 \% \mathrm{Cl}$ : $2-40 \%$ ). The number of children was not associated with any of the considered outcomes (Table 3 ). 
Table 3

Adjusted* Odds Ratios and $95 \% \mathrm{Cl}$ estimated by logistic regression models with dependent variables as self-reported diseases, autoimmune disorders, cardiovascular diseases, liver diseases, cancer, and pregnancy-related complications with respect to the reference

\begin{tabular}{|c|c|c|c|c|c|c|c|c|c|c|c|c|}
\hline & \multicolumn{2}{|c|}{$\begin{array}{l}\text { Self-reported } \\
\text { disease }\end{array}$} & \multicolumn{2}{|c|}{$\begin{array}{l}\text { Autoimmune } \\
\text { disorders }\end{array}$} & \multicolumn{2}{|c|}{$\begin{array}{l}\text { Cardiovascular } \\
\text { Diseases }\end{array}$} & \multicolumn{2}{|l|}{$\begin{array}{l}\text { Liver } \\
\text { diseases }\end{array}$} & \multicolumn{2}{|c|}{ Cancer } & \multicolumn{2}{|c|}{$\begin{array}{l}\text { Pregnancy } \\
\text { complications }\end{array}$} \\
\hline & OR & $95 \% \mathrm{Cl}$ & OR & $95 \% \mathrm{Cl}$ & $\mathrm{OR}$ & $95 \% \mathrm{Cl}$ & OR & $95 \% \mathrm{Cl}$ & OR & $95 \% \mathrm{Cl}$ & OR & $95 \% \mathrm{Cl}$ \\
\hline \multicolumn{13}{|l|}{$\begin{array}{l}\text { Environmental } \\
\text { factors }\end{array}$} \\
\hline $\begin{array}{l}\text { Residential } \\
\text { time [>20 } \\
\text { years] }\end{array}$ & 0.97 & $\begin{array}{l}0.62- \\
1.53\end{array}$ & 0.98 & $\begin{array}{l}0.53- \\
1.78\end{array}$ & 1.15 & $0.42-3.00$ & 0.88 & $\begin{array}{l}0.24- \\
3.08\end{array}$ & 2.15 & $\begin{array}{l}0.80- \\
5.92\end{array}$ & 0.87 & $\begin{array}{l}0.50- \\
1.47\end{array}$ \\
\hline $\begin{array}{l}\text { Red Zone } \\
\text { [Area A] }\end{array}$ & 0.87 & $\begin{array}{l}0.56- \\
1.37\end{array}$ & 1.15 & $\begin{array}{l}0.64- \\
2.07\end{array}$ & 1.63 & $0.60-4.73$ & 2.28 & $\begin{array}{l}0.61- \\
9.81\end{array}$ & 0.69 & $\begin{array}{l}0.25- \\
1.93\end{array}$ & 1.12 & $\begin{array}{l}0.67- \\
1.89\end{array}$ \\
\hline $\begin{array}{l}\text { Tap water } \\
\text { habit [+ } 1 \text { pt.] }\end{array}$ & 1.07 & $\begin{array}{l}1.01- \\
1.14\end{array}$ & 1.05 & $\begin{array}{l}0.97- \\
1.13\end{array}$ & 0.96 & $0.83-1.10$ & 0.88 & $\begin{array}{l}0.71- \\
1.06\end{array}$ & 1.21 & $\begin{array}{l}1.06- \\
1.40\end{array}$ & 1.06 & $\begin{array}{l}0.99- \\
1.14\end{array}$ \\
\hline \multicolumn{13}{|l|}{$\begin{array}{l}\text { Individual } \\
\text { factors }\end{array}$} \\
\hline $\begin{array}{l}\text { PFAS meas. } \\
\text { [Present- } \\
\text { PFOA } \leq 17 \\
\mathrm{ng} / \mathrm{mL}]\end{array}$ & 1.73 & $\begin{array}{l}1.01- \\
3.00\end{array}$ & 1.35 & $\begin{array}{l}0.67- \\
2.66\end{array}$ & 0.77 & $0.17-2.60$ & 1.08 & $\begin{array}{l}0.20- \\
4.49\end{array}$ & 1.06 & $\begin{array}{l}0.26- \\
3.55\end{array}$ & 1.24 & $\begin{array}{l}0.66- \\
2.27\end{array}$ \\
\hline $\begin{array}{l}\text { PFAS meas. } \\
\text { [Present- } \\
\text { PFOA }>17 \\
\mathrm{ng} / \mathrm{mL}]\end{array}$ & 1.40 & $\begin{array}{l}0.78- \\
2.52\end{array}$ & 0.80 & $\begin{array}{l}0.36- \\
1.71\end{array}$ & 1.22 & $0.37-3.67$ & 1.02 & $\begin{array}{l}0.18- \\
4.73\end{array}$ & 1.32 & $\begin{array}{l}0.39- \\
4.29\end{array}$ & 0.69 & $\begin{array}{l}0.33- \\
1.39\end{array}$ \\
\hline $\begin{array}{l}\text { PFAS } \\
\text { Perceived risk } \\
\text { [+ } 1 \text { pt.] }\end{array}$ & 1.14 & $\begin{array}{l}1.02- \\
1.28\end{array}$ & 1.19 & $\begin{array}{l}1.02- \\
1.40\end{array}$ & 1.04 & $0.82-1.35$ & 1.06 & $\begin{array}{l}0.78- \\
1.52\end{array}$ & 1.05 & $\begin{array}{l}0.81- \\
1.40\end{array}$ & 1.12 & $\begin{array}{l}0.98- \\
1.29\end{array}$ \\
\hline $\begin{array}{l}\text { Number of } \\
\text { Children [+ 1] }\end{array}$ & 0.92 & $\begin{array}{l}0.69- \\
1.21\end{array}$ & 0.77 & $\begin{array}{l}0.52- \\
1.12\end{array}$ & 1.04 & $0.57-1.79$ & 0.97 & $\begin{array}{l}0.44- \\
1.90\end{array}$ & 1.24 & $\begin{array}{l}0.70- \\
2.10\end{array}$ & 0.86 & $\begin{array}{l}0.62- \\
1.19\end{array}$ \\
\hline Observations & \multicolumn{2}{|l|}{384} & \multicolumn{2}{|l|}{384} & \multicolumn{2}{|c|}{384} & \multicolumn{2}{|l|}{384} & \multicolumn{2}{|c|}{384} & \multicolumn{2}{|l|}{384} \\
\hline $\mathrm{R}^{2} \mathrm{Tjur}$ & \multicolumn{2}{|l|}{0.069} & \multicolumn{2}{|l|}{0.028} & \multicolumn{2}{|c|}{0.036} & \multicolumn{2}{|l|}{0.056} & \multicolumn{2}{|c|}{0.134} & \multicolumn{2}{|l|}{0.035} \\
\hline
\end{tabular}

[ insert Table 3 here ]

PFAS concentration in the blood

The maternal PFAS concentrations for PFOA, PFOS, and PFHxS showed a median concentration of $17 \mathrm{ng} / \mathrm{mL}$ (IQR: $8-35$ ), $3.10 \mathrm{ng} / \mathrm{mL}$ (IQR: $2.30-4.20$ ), and $2.20 \mathrm{ng} / \mathrm{mL}$ (IQR: 1.40-3.40), respectively. When the blood was analyzed, participants from Red Zone A reported a higher concentration of all types of PFAS relative to those from Red Zone B (Table S1). The concentrations of PFAS showed significant pairwise positive correlations, particularly between PFOA and PFHxS (Pearson's correlation: 0.822, p<0.001) (Fig. 3).

[ insert Fig. 3 here ]

The most important characteristics of the mothers concerning the concentration of PFOA, based on the median PFOA level, were the residence time $(p<0.001)$, residence in the Red Zone A or $B(p<0.001)$, number of children before $2008(p<0.001)$, breastfeeding duration of the first child $(p<0.001)$, and the consumption of tap water $(p=0.021)$ (Table 4$)$. 
Table 4

The characteristics of the participants with PFAS measurements for the overall level and the PFOA level.

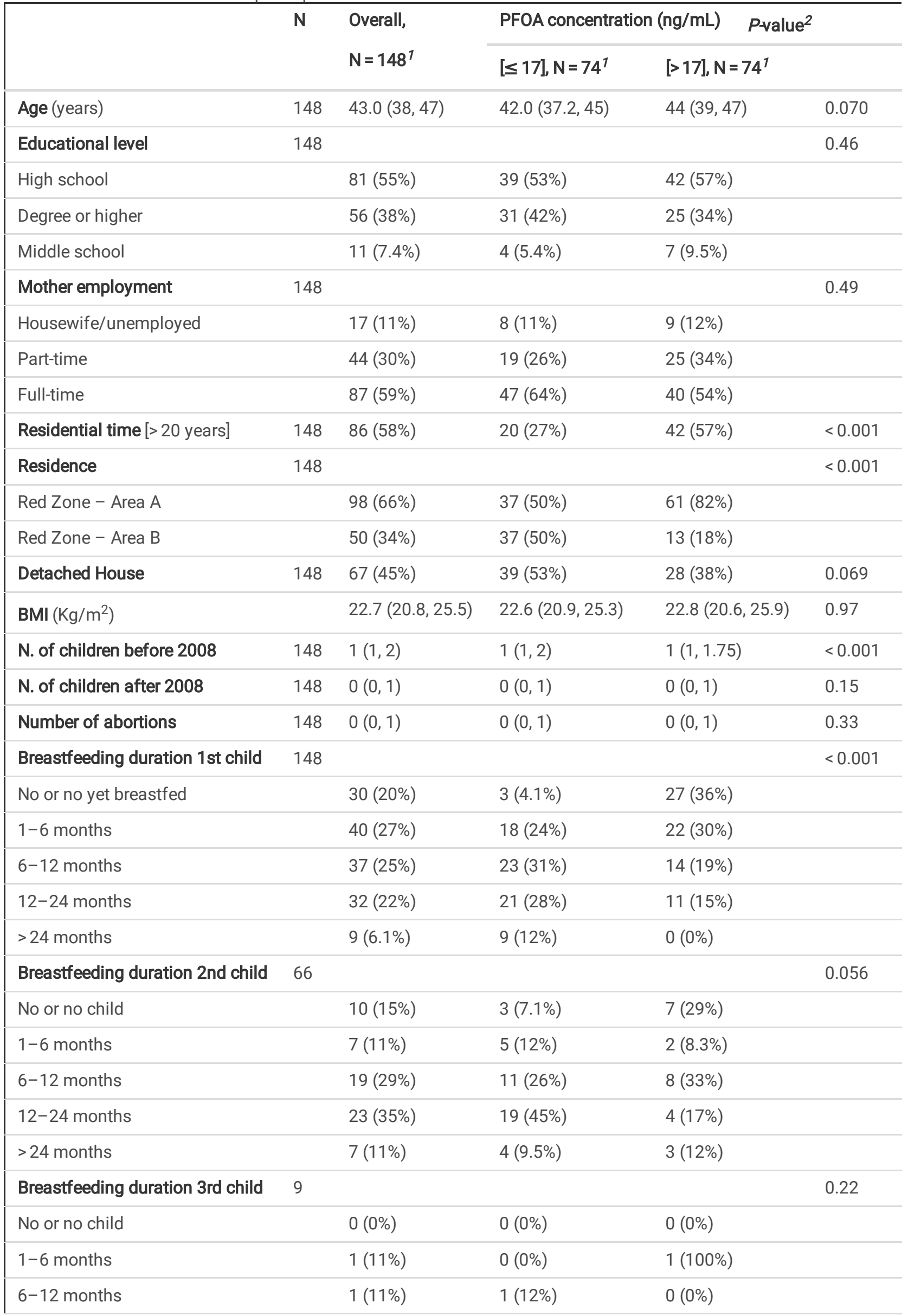




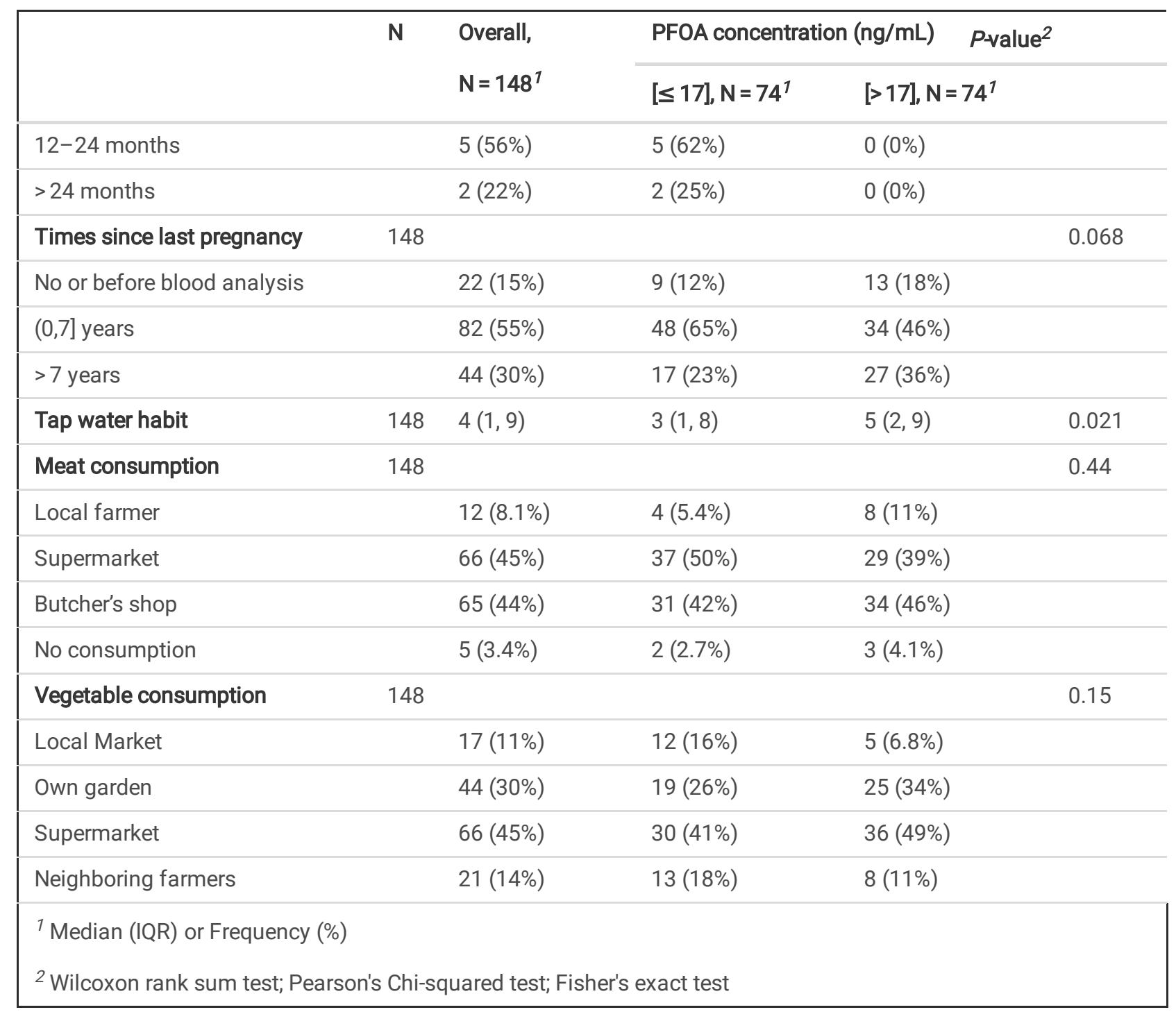

[ insert Table 4 here ]

The results of the regression model based on the log-PFAS concentration are summarized in Table 5. In each model, all the variables related to pregnancy and to residence time explained a discrete level of variance (Table S2). For variables not related to pregnancy, consumption of tap water was associated with an increase in both the log-PFOA and log-PFHxS levels. The interaction between tap water consumption and the residence time (Table 4, Fig. 4) showed a higher increase in the log-PFOA and log-PFHxS levels for those who were long-time residents (> 20 years) than in the short-time residents. 
Table 5

The coefficients estimated by regression models for the log-PFAS concentration with respect to the reference category*.

\begin{tabular}{|c|c|c|c|c|c|c|c|c|c|}
\hline \multirow[b]{2}{*}{ Predictors } & \multicolumn{3}{|c|}{ Log-PFOA Model } & \multicolumn{4}{|c|}{ Log-PFOS Model } & \multicolumn{2}{|c|}{ Log-PFHxS Model } \\
\hline & Est. & $95 \% \mathrm{Cl}$ & $\begin{array}{l}\mathrm{P} \text { - } \\
\text { value }\end{array}$ & Est. & $95 \% \mathrm{Cl}$ & $\begin{array}{l}\mathrm{P}- \\
\text { value }\end{array}$ & Est. & $95 \% \mathrm{Cl}$ & $\begin{array}{l}P \text { - } \\
\text { value }\end{array}$ \\
\hline (Intercept) & 3.48 & $2.94-4.02$ & $\dot{0} .001$ & 1.64 & $1.02-2.26$ & $\dot{0} 001$ & 1.59 & $1.13-2.06$ & $\dot{\zeta} 001$ \\
\hline Tap water habit [+ 1 pt.] & 0.09 & $0.03-0.16$ & 0.004 & & & & 0.09 & $0.04-0.14$ & 0.001 \\
\hline Residential time [> 20 years] & -0.08 & $-0.36-0.51$ & 0.725 & 0.47 & $\begin{array}{l}-0.67- \\
-0.27\end{array}$ & $\dot{0} 001$ & 0.56 & $\begin{array}{l}-0.79- \\
-0.33\end{array}$ & $\dot{5} 001$ \\
\hline $\begin{array}{l}\text { Tap Water * Residential time [> } 20 \\
\text { years] }\end{array}$ & 0.10 & $\begin{array}{l}-0.18- \\
-0.03\end{array}$ & 0.006 & & & & 0.07 & $\begin{array}{l}-0.14- \\
-0.01\end{array}$ & 0.022 \\
\hline Red Zone [B] & -1.09 & $\begin{array}{l}-1.54- \\
-0.65\end{array}$ & $<.001$ & -0.33 & $\begin{array}{l}-0.50- \\
-0.16\end{array}$ & $\hat{0} 001$ & -0.53 & $\begin{array}{l}-0.77- \\
-0.30\end{array}$ & $\dot{0} 001$ \\
\hline Tap Water * Red Zone [B] & 0.08 & $0.00-0.16$ & 0.042 & & & & & & \\
\hline Meat [Local meat] & 0.33 & $-0.16-0.82$ & 0.189 & & & & 0.26 & $\begin{array}{l}-0.19- \\
0.71\end{array}$ & 0.262 \\
\hline Meat [Butcher's shop] & 0.10 & $-0.17-0.36$ & 0.465 & & & & -0.01 & $\begin{array}{l}-0.23- \\
0.24\end{array}$ & 0.946 \\
\hline Meat [No-consumption] & 0.76 & $0.04-1.48$ & 0.040 & & & & 0.71 & $0.09-1.32$ & 0.025 \\
\hline Vegetables [Local market] & & & & -0.23 & $-0.50-0.03$ & 0.085 & & & \\
\hline Vegetables [Own garden] & & & & 0.27 & $0.08-0.47$ & 0.006 & & & \\
\hline Vegetables [Neighboring farmers] & & & & -0.09 & $-0.33-0.15$ & 0.470 & & & \\
\hline $\mathrm{BMI}\left(+1 \mathrm{Kg} / \mathrm{m}^{2}\right)$ & & & & -0.02 & $-0.04-0.00$ & 0.090 & & & \\
\hline Detached house [Yes] & -0.40 & $\begin{array}{l}-0.65- \\
-0.15\end{array}$ & 0.002 & & & & -0.19 & $\begin{array}{l}-0.41- \\
0.02\end{array}$ & 0.075 \\
\hline N. children before $2008[+1]$ & -0.24 & $\begin{array}{l}-0.43- \\
-0.05\end{array}$ & 0.013 & 0.24 & $-0.01-0.48$ & 0.058 & -0.29 & $\begin{array}{l}-0.47- \\
-0.11\end{array}$ & 0.002 \\
\hline N. children after $2008[+1]$ & & & & & & & -0.14 & $\begin{array}{l}-0.30- \\
0.01\end{array}$ & 0.076 \\
\hline N. of abortions [+ 1] & & & & -0.22 & $\begin{array}{l}-0.35- \\
-0.09\end{array}$ & 0.001 & & & \\
\hline N. of abortions [+ 1]* Red Zone [B] & & & & 0.24 & $0.06-0.42$ & 0.009 & & & \\
\hline $\begin{array}{l}\text { Time since last pregnancy [0-7 } \\
\text { years] }\end{array}$ & 0.13 & $-0.27-0.53$ & 0.525 & 0.14 & $-0.11-0.38$ & 0.272 & & & \\
\hline $\begin{array}{l}\text { Time since last pregnancy [> } 7 \\
\text { years] }\end{array}$ & 0.48 & $0.02-0.95$ & 0.041 & 0.39 & $0.11-0.67$ & 0.007 & & & \\
\hline $\begin{array}{l}\text { Breastfeeding 1st child [1-6 } \\
\text { months] }\end{array}$ & -0.30 & $-0.68-0.08$ & 0.121 & -0.19 & $-0.43-0.05$ & 0.124 & -0.34 & $\begin{array}{l}-0.65- \\
-0.03\end{array}$ & 0.034 \\
\hline $\begin{array}{l}\text { Breastfeeding 1st child [6-12 } \\
\text { months] }\end{array}$ & -0.62 & $\begin{array}{l}-1.02- \\
-0.21\end{array}$ & 0.003 & -0.38 & $\begin{array}{l}-0.64- \\
-0.12\end{array}$ & 0.005 & -0.36 & $\begin{array}{l}-0.69- \\
-0.04\end{array}$ & 0.029 \\
\hline $\begin{array}{l}\text { Breastfeeding 1st child [12-24 } \\
\text { months] }\end{array}$ & -0.71 & $\begin{array}{l}-1.13- \\
-0.29\end{array}$ & 0.001 & -0.14 & $-0.42-0.13$ & 0.306 & -0.33 & $\begin{array}{l}-0.66- \\
0.00\end{array}$ & 0.051 \\
\hline $\begin{array}{l}\text { Breastfeeding 1st child [ }>24 \\
\text { months] }\end{array}$ & -1.29 & $\begin{array}{l}-1.92- \\
-0.65\end{array}$ & ¿. 001 & -0.23 & $-0.62-0.17$ & 0.253 & -0.82 & $\begin{array}{l}-1.33- \\
-0.31\end{array}$ & 0.002 \\
\hline
\end{tabular}

${ }^{*}$ Residence [ 20 years], Red Zone [A], Meat [Supermarket], Vegetables [Supermarket], Breastfeeding 1st child [No], Breastfeeding 2nd child [No], Breastfeeding 3rd child [No], Detached house [No], Time since last pregnancy [No or before blood analysis]. 


\begin{tabular}{|c|c|c|c|c|c|c|c|}
\hline \multirow[b]{2}{*}{$\begin{array}{l}\text { Breastfeeding 2nd child [1-6 } \\
\text { months] }\end{array}$} & \multicolumn{3}{|c|}{ Log-PFOA Model } & \multicolumn{3}{|c|}{ Log-PFOS Model } & \multirow[t]{2}{*}{ Log-PFHxS Model } \\
\hline & -0.49 & $-1.08-0.11$ & 0.109 & -0.40 & $-0.83-0.03$ & 0.066 & \\
\hline $\begin{array}{l}\text { Breastfeeding 2nd child [6-12 } \\
\text { months] }\end{array}$ & -0.32 & $-0.73-0.09$ & 0.123 & -0.35 & $-0.72-0.01$ & 0.059 & \\
\hline $\begin{array}{l}\text { Breastfeeding 2nd child [12-24 } \\
\text { months] }\end{array}$ & -0.45 & $\begin{array}{l}-0.87- \\
-0.04\end{array}$ & 0.032 & -0.12 & $-0.48-0.25$ & 0.531 & \\
\hline $\begin{array}{l}\text { Breastfeeding 2nd child [> } 24 \\
\text { months] }\end{array}$ & -0.69 & $\begin{array}{l}-1.32- \\
-0.05\end{array}$ & 0.034 & -0.64 & $\begin{array}{l}-1.11- \\
-0.17\end{array}$ & 0.008 & \\
\hline Breastfeeding 3rd child [Yes] & -0.75 & $\begin{array}{l}-1.31- \\
-0.19\end{array}$ & 0.009 & & & & \\
\hline Observations/Predictors & \multicolumn{3}{|c|}{$148 / 10$} & \multicolumn{3}{|c|}{$146 / 9$} & $145 / 7$ \\
\hline $\mathrm{R}^{2} / \mathrm{R}^{2}$ adjusted $/ \mathrm{Q}^{2}$ & \multicolumn{3}{|c|}{$0.606 / 0.540 / 0.458$} & \multicolumn{3}{|c|}{$0.386 / 0.294 / 0.219$} & $0.401 / 0.352 / 0.299$ \\
\hline
\end{tabular}

[insert Fig. 4 here ]

Living in Red Zone B was associated with a lower PFAS concentration ( $p<0.001$ for the three models). For the interaction with tap water consumption, the log-PFOA model indicated a differential effect of drinking tap water with the residence zone $(p=0.042$, Fig. 4). Food consumption explained a limited level of variance (Table S2); specifically, local meat consumption and the lack of meat consumption increased log-PFOA and log-PFHxS levels, compared to the levels for those who consumed meat from the supermarket. The consumption of vegetables grown in the garden of the participants was associated with higher log-PFOS values relative to the values for those participants who bought vegetables from the supermarket. Living in a detached house was also associated with reduced log-PFOA and log-PFHxS levels ( $p=0.002$ and $p=0.075$, respectively) relative to the levels in those living in other types of houses. Overall, the variance explained by the pregnancy-related predictors was high, specifically for the log-PFOA concentration (Table S2; 36\% PFOA, 17\% PFOS, and $17 \%$ PFHxS).

The number of children conceived before 2008 was negatively associated with the log-PFOA and log-PFHxS concentrations. The number of abortions was negatively associated with the log-PFOS levels $(p=0.001)$, particularly, in mothers living in Red Zone A (Fig. 4). Conversely, the concentrations of PFOA and PFOS were positively associated with time since the last pregnancy. A progressive reduction in the log-PFOA concentrations was associated with longer breastfeeding of the first, second, and third child. This reduction was also significant for PFOS levels, but only for the first two pregnancies between 2008 and 2018, while for PFHxS, the association was limited to the breastfeeding of the first child only (Table 5).

The total variance explained by the models for log-PFOA, PFOS, and PFHxS was $54.0 \%, 29.4 \%$, and $35.2 \%$, respectively ( $R^{2}$ adjusted). However, only the model that estimated the log-PFOA concentration showed a good predictive power $\left(Q^{2}=45.8 \%\right)$.

[ insert Table 5 here ]

\section{Discussion}

This study assessed mothers (of young children) living in a severely PFAS-contaminated region. These mothers were exposed to elevated levels of PFOA through drinking water till 2017. The data was used to determine the environmental and individual factors that might influence the perception of health risks due to exposure to PFAS. Additionally, we investigated whether perceived risk, along with environmental factors linked to PFAS exposure, was associated with self-reported diseases in the mothers. From some of the participants, we also evaluated the real environmental and individual influencing factors that might be associated with the serum PFAS levels in the mothers.

The perceived risk of being exposed to PFAS was strongly associated with the trust in scientific and political institutions and information from social media. We found that the risk perception of the participants was associated with the information provided to the public by institutions and the media (Goldstein, 2017). PFAS contamination is often "invisible", i.e., individuals are unable to detect such substances in the water or food. Moreover, the effects are uncertain, and there is a long gap between the first exposure and the detection

Page $12 / 21$ 
of contamination and possible consequences in individuals (Goldstein, 2017). Interestingly, the trust in scientific institutions was positively associated with perceived risk; thus, indicating that those who had greater trust in scientific information perceived stronger detrimental effects of PFAS (Steenland et al., 2020). The effect of trust in political institutions was strongly associated with the reduction in perceived risk. After the detection of PFAS contamination, the local authority equipped water treatment plants with granular activated carbon filters, while a surveillance program of the exposed population was conducted (Pitter et al., 2020). The trust in these mitigation and health measures reduced the perception of risk (Viklund et al., 2003). Previous studies have reported several common concerns of the members of the community who faced PFAS contamination: health issues due to unhygienic living conditions, loss of confidence in governmental institutions, feeling insecure, frustration, and lack of control/agency over the situation; all these issues can be resolved by a renewed trust in political institutions (Calloway et al., 2020). Conversely, trust in information on social media reshapes public risk perception by increasing self-reported knowledge (Liu et al., 2021). Within the population of child-bearing women, those who were fulltime employees perceived a lower PFAS health risk than housewives or unemployed individuals, suggesting that maternity (probably linked to the status of housewife or unemployment) might make them more worried about their children's future (Signorino, 2012). Previous studies (Jetten et al., 2012) suggested that having a strong network of friends imparts psychological benefits, but in this context, it might contribute to amplifying the perceived risk. Specifically, within the population of the mothers living in the "red zone" (highly contaminated), mothers with a wider social network were more connected to the community and were frequently reminded of the possible risks of environmental contamination.

The analysis of the self-reported diseases showed that mothers with higher risk perception related to PFAS exposure reported more health issues and autoimmune disorders. Similarly, participants in the surveillance program with known PFAS levels showed higher occurrences of self-reported diseases. High-risk perception is associated with a change in the lifestyle and adoption of health-protective measures (Gerber \& Neeley, 2005; Coi et al., 2016). Exposure to chronic environmental pollution was associated with an increase in the general distress among contaminated communities because these individuals face uncertainty, worries related to health risks (cancer clusters, unexplained deaths, worsening health conditions, and the future health of children) (Calloway et al., 2020; Banwell et al., 2021), and the potential of further being exposed to the contaminants every day (e.g., water sources and usage) (Calloway et al., 2020). A continuous and high-stress response can cause immune dysregulation, which might lead to autoimmune disease by altering or amplifying cytokine production (Stojanovich et al., 2009).

Among environmental factors, consumption of tap water was associated with more reports on health issues, particularly of cancer, as well as a longer residence time. The residents of Red Zone A had two times higher risk of liver diseases than those of Red Zone B. Drinking contaminated water is a well-known source of PFAS exposure (Domingo \& Nadal, 2019). This could be a reason for the longterm residents of Red Zone A to report a higher PFAS concentration (Pitter et al., 2020). Several studies found an association between PFAS exposure and markers of liver diseases (Armstrong et al., 2019; Bassler et al., 2019), while the association between PFAS exposure and common types of cancer in young mothers (e.g., breast cancer) showed mixed results (Bonefeld-Jørgensen et al., 2014; Hurley et al., 2018; Tsai et al., 2020). Additionally, a higher risk of cardiovascular diseases was reported in residents of Red Zone A compared to those living in Red Zone B. This result was similar to that found in previous studies that showed an association between serum blood PFAS concentration and the risk of cardiovascular diseases (Shankar et al., 2012; Huang et al., 2018), where a platelet-centered mechanism might be the biological link (De Toni et al., 2020; Meneguzzi et al., 2021).

Factors derived from environmental contamination, such as the contamination of food, may or may not be associated with real exposure (Dettori et al., 2020), and this discrepancy can be modulated by a combination of objective (e.g., exposure levels) and subjective factors (e.g., socioeconomic conditions and cultural values). In this study, we evaluated which factors influenced PFAS levels among mothers of young children. Pregnancy-related variables (breastfeeding, number of abortions, number of children, and time since last pregnancy) were the major determinants of PFAS levels in the mother's blood. Breastfeeding significantly influenced all log-PFAS models, especially the log-PFOA model, which estimated a large effect up to the birth of the third child. This result confirmed that mothers who breastfed exhibited lower PFAS concentrations than those who did not breastfeed. A significant quantity of PFAS can be removed from the body through breast milk (Mondal et al., 2014). Conversely, PFAS can be passed through breastfeeding from the mother to nursed infants and accumulate with the PFAS from prenatal placental transfer and postnatal exposure to contaminants (e.g., through environmental exposure, diet, or tap water consumption) (Kim et al., 2020). We found that the area of residence was another significant predictor of PFAS concentration in the mother's blood (Pitter et al., 2020). Based on our analysis, individuals living in the municipalities of the Red Zone located above the site of groundwater contamination (Red Zone A) showed a higher blood PFAS level than those residing outside (Red Zone B). Additionally, participants from municipalities outside Red Zone A showed lower PFAS concentrations, especially when they consumed tap water less often. The association between PFAS levels and other variables, such as the source of meat or vegetables, was lower in our study than that reported for the general population (Brantsaeter et al., 2013; Berg et al., 2014).

Page 13/21 
Most of the questionnaires were completed by the participants. From some of the participants, we also obtained a measure of the serum blood PFAS concentration. The variables recorded allowed us to conduct three types of analyses to address specific research questions. This was the first study to simultaneously analyze the perceived risk, health outcomes, and PFAS determinants in the same population. Some results, especially those regarding the determinants of PFAS concentration, are very important (Mondal et al., 2014). This study had a small sample size, which might affect the generalizability of our results. Moreover, the participants were mothers who volunteered to participate in an online survey that was mainly spread through word-of-mouth. The online modality implied a certain selection bias since certain types of participants were under-represented, for example, those with a low education level. Basically, the cross-sectional nature of the study and self-reporting of diseases limited the causal attribution of the results. To overcome this latter point, we introduced some confounding variables in the analysis (e.g., age, education level, and employment status) to keep into account the non-probability sampling and to perform an adjustment of the risk estimates. In terms of health outcomes, we grouped and analyzed several diseases into a single comprehensive category, which limited our ability to derive strong associations between the PFAS measures and a specific disease.

\section{Conclusions}

This study was the first to be conducted from a highly PFAS-contaminated area in Italy that examined perceived risk and factors influencing the PFAS concentration in mothers with young children. The perceived health risk due to PFAS exposure was associated with the trust in the scientific and political institutions and social media. Mothers who trust scientific institutions and social media perceive greater risk, and thus, might report having more diseases. The protective effect due to trust in political institutions confirmed that the periodicity of the circulation of information and the reliability of the data presented to the residents are important for reducing perceived risk (Liu et al., 2021). However, comprehensive epidemiological studies at a large scale are required to determine the association between the occurrences of some diseases and the historical PFAS exposure, where the population of mothers living outside the contaminated area might be considered as a parameter of comparison. Breastfeeding considerably reduced PFAS levels in mothers and increased the levels in infants; preventive health measures can promote the screening of PFAS serum levels in future mothers and inform them of the potential adverse effects on infants of breastfeeding by individuals with high levels of PFAS. Intervention programs should be introduced and aimed at psychologically supporting these mothers to promote parenting practices that support a positive mother-infant relationship. Furthermore, research programs should concentrate on assessing the influence of PFAS on the health and development of children (Harris et al., 2021).

\section{Declarations}

Funding: This study was supported by an unrestricted grant to the Department of Developmental and Social Psychology, University of Padova, grant number BIRD205128 (PI: Paolo Girardi). The funders did not design the study. They did not collect, analyze, interpret the data, or write the manuscript. They played no role in the decision to publish the results.

Ethical Approval: The study was approved by the ethical committee of the researchers' university (Protocol number 4051).

Informed Consent Statement: Informed consent was obtained from all the participants involved in the study.

Data Availability Statement: The dataset generated during and/or analyzed during the current study is available from the corresponding author upon reasonable request.

Conflicts of Interest: The authors declare no conflict of interest.

Author Contributions: Conceptualization: P.G., A.L., and S.S.; methodology and formal analysis: P.G.; validation: P.G., A.L., and S.S.; investigation: P.G., L.M., and S.S.; funding acquisition: P.G., A.L., and S.S.; data curation: S.L. and L.M.; writing-original draft preparation: P.G., A.L., and S.S.; writing-review and editing: P.G., A.L, L.M., and S.S.; supervision: P.G. and S.S. All authors have read and agreed to the published version of the manuscript.

\section{References}

1. Amrhein, V., Greenland, S., \& McShane, B. (2019). Scientists rise up against statistical significance. Nature, 567, 305-307. http://dx.doi.org/10.1038/d41586-019-00857-9. 
2. Armstrong, L. E., \& Guo, G. L. (2019). Understanding environmental contaminants' direct effects on non-alcoholic fatty liver disease progression. Current environmental health reports, 6(3), 95-104. http://dx.doi.org/10.1007/s40572-019-00231-x.

3. Apelberg, B. J., Witter, F. R., Herbstman, J. B., Calafat, A. M., Halden, R. U., Needham, L. L., \& Goldman, L. R. (2007). Cord serum concentrations of perfluorooctane sulfonate (PFOS) and perfluorooctanoate (PFOA) in relation to weight and size at birth. Environmental health perspectives, 115(11), 1670-1676. http://dx.doi.org/10.1289/ehp.10334.

4. Averina, M., Brox, J., Huber, S., \& Furberg, A. S. (2021). Exposure to perfluoroalkyl substances (PFAS) and dyslipidemia, hypertension and obesity in adolescents. The Fit Futures study. Environmental Research, 195, 110740. http://dx.doi.org/10.1016/j.envres.2021.110740.

5. Banwell, C., Housen, T., Smurthwaite, K., Trevenar, S., Walker, L., Todd, K., ... \& Kirk, M. (2021). Health and social concerns about living in three communities affected by per-and polyfluoroalkyl substances (PFAS): A qualitative study in Australia. Plos one, 16(1), e0245141. http://dx.doi.org/10.1371/journal.pone.0245141.

6. Bassler, J., Ducatman, A., Elliott, M., Wen, S., Wahlang, B., Barnett, J., \& Cave, M. C. (2019). Environmental perfluoroalkyl acid exposures are associated with liver disease characterized by apoptosis and altered serum adipocytokines. Environmental Pollution, 247, 1055-1063. http://dx.doi.org/10.1016/j.envpol.2019.01.064.

7. Berg, V., Nøst, T. H., Huber, S., Rylander, C., Hansen, S., Veyhe, A. S., ... \& Sandanger, T. M. (2014). Maternal serum concentrations of per-and polyfluoroalkyl substances and their predictors in years with reduced production and use. Environment international, 69, 5866. http://dx.doi.org/10.1016/j.envint.2014.04.010.

8. Blake, B. E., Pinney, S. M., Hines, E. P., Fenton, S. E., \& Ferguson, K. K. (2018). Associations between longitudinal serum perfluoroalkyl substance (PFAS) levels and measures of thyroid hormone, kidney function, and body mass index in the Fernald Community Cohort. Environmental pollution, 242, 894-904. http://dx.doi.org/10.1016/j.envpol.2018.07.042.

9. Bommarito, P. A., Ferguson, K. K., Meeker, J. D., McElrath, T. F., \& Cantonwine, D. E. (2021). Maternal Levels of Perfluoroalkyl Substances (PFAS) during Early Pregnancy in Relation to Preeclampsia Subtypes and Biomarkers of Preeclampsia Risk. Environmental health perspectives, 129(10), 107004. http://dx.doi.org/10.1289/EHP9091.

10. Bonefeld-Jørgensen, E. C., Long, M., Fredslund, S. O., Bossi, R., \& Olsen, J. (2014). Breast cancer risk after exposure to perfluorinated compounds in Danish women: a case-control study nested in the Danish National Birth Cohort. Cancer Causes \& Control, 25(11), 1439-1448. http://dx.doi.org/10.1007/s10552-014-0446-7.

11. Borghese, M. M., Walker, M., Helewa, M. E., Fraser, W. D., \& Arbuckle, T. E. (2020). Association of perfluoroalkyl substances with gestational hypertension and preeclampsia in the MIREC study. Environment international, 141, 105789. http://dx.doi.org/10.1016/j.envint.2020.105789.

12. Brantsaeter, A. L., Whitworth, K. W., Ydersbond, T. A., Haug, L. S., Haugen, M., Knutsen, H. K., ... \& Longnecker, M. P. (2013). Determinants of plasma concentrations of perfluoroalkyl substances in pregnant Norwegian women. Environment international, 54, 74-84. http://dx.doi.org/10.1016/j.envint.2012.12.014.

13. Buck, R. C., Franklin, J., Berger, U., Conder, J. M., Cousins, I. T., De Voogt, P., ... \& van Leeuwen, S. P. (2011). Perfluoroalkyl and polyfluoroalkyl substances in the environment: terminology, classification, and origins. Integrated environmental assessment and management, 7(4), 513-541. http://dx.doi.org/10.1002/ieam.258.

14. Coi, A., Minichilli, F., Bustaffa, E., Carone, S., Santoro, M., Bianchi, F., \& Cori, L. (2016). Risk perception and access to environmental information in four areas in Italy affected by natural or anthropogenic pollution. Environment International, 95, 8-15. http://dx.doi.org/10.1016/j.envint.2016.07.009.

15. Calloway, E. E., Chiappone, A. L., Schmitt, H. J., Sullivan, D., Gerhardstein, B., Tucker, P. G., ... \& Yaroch, A. L. (2020). Exploring community psychosocial stress related to per-and poly-fluoroalkyl substances (PFAS) contamination: lessons learned from a qualitative study. International journal of environmental research and public health, 17(23), 8706. http://dx.doi.org/10.3390/ijerph17238706.

16. Conder, J. M., Hoke, R. A., Wolf, W. D., Russell, M. H., \& Buck, R. C. (2008). Are PFCAs bioaccumulative? A critical review and comparison with regulatory criteria and persistent lipophilic compounds. Environmental science \& technology, 42(4), 995-1003. http://dx.doi.org/10.1021/es070895g.

17. Costello, E., Rock, S., Stratakis, N., Eckel, S., Walker, D. I., Valvi, D., ... \& Chatzi, L. (2021). Exposure to perfluoroalkyl substances (PFAS) and liver injury: a systematic review and meta-analysis. In ISEE Conference Abstracts (Vol. 2021, No. 1).

http://dx.doi.org/10.1289/isee.2021.P-716. 
18. Crighton, E. J., Brown, C., Baxter, J., Lemyre, L., Masuda, J. R., \& Ursitti, F. (2013). Perceptions and experiences of environmental health risks among new mothers: a qualitative study in Ontario, Canada. Health, Risk \& Society, 15(4), $295-312$. http://dx.doi.org/10.1080/13698575.2013.796345.

19. De Toni, L., Radu, C. M., Sabovic, I., Di Nisio, A., Dall'Acqua, S., Guidolin, D., ... \& Foresta, C. (2020). Increased cardiovascular risk associated with chemical sensitivity to perfluoro-octanoic acid: role of impaired platelet aggregation. International journal of molecular sciences, 21(2), 399. http://dx.doi.org/10.3390/ijms21020399.

20. Dettori, M., Pittaluga, P., Busonera, G., Gugliotta, C., Azara, A., Piana, A., ... \& Castiglia, P. (2020). Environmental risks perception among citizens living near industrial plants: a cross-sectional study. International Journal of Environmental Research and Public Health, 17(13), 4870. http://dx.doi.org/10.3390/ijerph17134870.

21. Di Nisio, A., Rocca, M. S., Sabovic, I., Ponce, M. D. R., Corsini, C., Guidolin, D., ... \& Foresta, C. (2020). Perfluorooctanoic acid alters progesterone activity in human endometrial cells and induces reproductive alterations in young women. Chemosphere, $242,125208$. http://dx.doi.org/10.1016/j.chemosphere.2019.125208.

22. Domingo, J. L., \& Nadal, M. (2019). Human exposure to per-and polyfluoroalkyl substances (PFAS) through drinking water: a review of the recent scientific literature. Environmental research, 177, 108648. http://dx.doi.org/10.1016/j.envres.2019.108648.

23. Emmett, E. A., Shofer, F. S., Zhang, H., Freeman, D., Desai, C., \& Shaw, L. M. (2006). Community exposure to perfluorooctanoate: relationships between serum concentrations and exposure sources. Journal of occupational and environmental medicine/American College of Occupational and Environmental Medicine, 48(8), 759. http://dx.doi.org/10.1097/01.jom.0000232486.07658.74.

24. Frisbee, S. J., Brooks Jr, A. P., Maher, A., Flensborg, P., Arnold, S., Fletcher, T., ... \& Ducatman, A. M. (2009). The C8 health project: design, methods, and participants. Environmental health perspectives, 117(12), 1873-1882. http://dx.doi.org/10.1289/ehp.0800379.

25. Fromme, H., Mosch, C., Morovitz, M., Alba-Alejandre, I., Boehmer, S., Kiranoglu, M., ... \& Völkel, W. (2010). Pre-and postnatal exposure to perfluorinated compounds (PFCs). Environmental science \& technology, 44(18), 7123-7129. http://dx.doi.org/10.1021/es101184f.

26. Gerber, B. J., \& Neeley, G. W. (2005). Perceived risk and citizen preferences for governmental management of routine hazards. Policy Studies Journal, 33(3), 395-418. http://dx.doi.org/10.1111/j.1541-0072.2005.00122.x.

27. Girardi, P., \& Merler, E. (2019). A mortality study on male subjects exposed to polyfluoroalkyl acids with high internal dose of perfluorooctanoic acid. Environmental Research, 179, 108743. http://dx.doi.org/10.1016/j.envres.2019.108743.

28. Goldstein, D. M. (2017). Invisible harm: science, subjectivity and the things we cannot see. Culture, Theory and Critique, 58(4), 321329. http://dx.doi.org/10.1080/14735784.2017.1365310.

29. Grandjean, P., Heilmann, C., Weihe, P., Nielsen, F., Mogensen, U. B., Timmermann, A., \& Budtz-Jørgensen, E. (2017). Estimated exposures to perfluorinated compounds in infancy predict attenuated vaccine antibody concentrations at age 5-years. Journal of immunotoxicology, 14(1), 188-195. http://dx.doi.org/10.1080/1547691X.2017.1360968.

30. Harris, M. H., Oken, E., Rifas-Shiman, S. L., Calafat, A. M., Bellinger, D. C., Webster, T. F., ... \& Sagiv, S. K. (2021). Prenatal and childhood exposure to per-and polyfluoroalkyl substances (PFAS) and child executive function and behavioral problems. Environmental Research, 202, 111621. http://dx.doi.org/10.1016/j.envres.2021.111621.

31. Huang, M., Jiao, J., Zhuang, P., Chen, X., Wang, J., \& Zhang, Y. (2018). Serum polyfluoroalkyl chemicals are associated with risk of cardiovascular diseases in national US population. Environment International, 119, 37-46.

http://dx.doi.org/10.1016/j.envint.2018.05.051.

32. Hurley, S., Goldberg, D., Wang, M., Park, J. S., Petreas, M., Bernstein, L., ... \& Reynolds, P. (2018). Breast cancer risk and serum levels of per-and poly-fluoroalkyl substances: A case-control study nested in the California Teachers Study. Environmental Health, 17(1), 1-19. http://dx.doi.org/10.1186/s12940-018-0426-6.

33. Ingelido, A. M., Abballe, A., Gemma, S., Dellatte, E., lacovella, N., De Angelis, G., ... \& De Felip, E. (2018). Biomonitoring of perfluorinated compounds in adults exposed to contaminated drinking water in the Veneto Region, Italy. Environment international, 110, 149-159. http://dx.doi.org/10.1016/j.envint.2017.10.026.

34. Jetten, J., Haslam, C., \& Alexander, S. H. (Eds.). (2012). The social cure: Identity, health and well-being. Psychology press.

35. Jusko, T. A., Oktapodas, M., Palkovičová Murinová, L. U., Babinská, K., Babjaková, J., Verner, M. A., ... \& Lamoree, M. H. (2016). Demographic, reproductive, and dietary determinants of perfluorooctane sulfonic (PFOS) and perfluorooctanoic acid (PFOA) concentrations in human colostrum. Environmental science \& technology, 50(13), 7152-7162.

http://dx.doi.org/10.1021/acs.est.6b00195. 
36. Kim, K., Bennett, D. H., Calafat, A. M., Hertz-Picciotto, I., \& Shin, H. M. (2020). Temporal trends and determinants of serum concentrations of per-and polyfluoroalkyl substances among Northern California mothers with a young child, 2009-2016. Environmental Research, 186, 109491. http://dx.doi.org/10.1016/j.envres.2020.109491.

37. Lava, R., Calore, F., Mazzola, M., Moretto, C. G., Pretto, U., Salmaso, P., ... \& Marcomini, A. (2021). Groundwater contamination by fluorinated aromatics: Benzotrifluoride and its derivatives. Chemosphere, 265, 129029. http://dx.doi.org/10.1016/j.chemosphere.2020.129029.

38. Liu, M., Bi, J., Yang, J., Qu, S., \& Wang, J. (2021). Social media never shake the role of trust building in relieving public risk perception. Journal of Cleaner Production, 282, 124442. http://dx.doi.org/10.1016/j.jclepro.2020.124442.

39. Manzano-Salgado, C. B., Casas, M., Lopez-Espinosa, M. J., Ballester, F., Basterrechea, M., Grimalt, J. O., ... \& Vrijheid, M. (2015). Transfer of perfluoroalkyl substances from mother to fetus in a Spanish birth cohort. Environmental Research, 142, 471-478. http://dx.doi.org/10.1016/j.envres.2015.07.020.

40. Manzano-Salgado, C. B., Casas, M., Lopez-Espinosa, M. J., Ballester, F., Martinez, D., Ibarluzea, J., ... \& Vrijheid, M. (2016). Variability of perfluoroalkyl substance concentrations in pregnant women by sociodemographic and dietary factors in a Spanish birth cohort. Environment International, 92, 357-365. http://dx.doi.org/10.1016/j.envint.2016.04.004.

41. Meneguzzi, A., Fava, C., Castelli, M., \& Minuz, P. (2021). Exposure to perfluoroalkyl chemicals and cardiovascular disease: experimental and epidemiological evidence. Frontiers in Endocrinology, 12, 850. http://dx.doi.org/10.3389/fendo.2021.706352.

42. Mondal, D., Weldon, R. H., Armstrong, B. G., Gibson, L. J., Lopez-Espinosa, M. J., Shin, H. M., \& Fletcher, T. (2014). Breastfeeding: a potential excretion route for mothers and implications for infant exposure to perfluoroalkyl acids. Environmental health perspectives, 122(2), 187-192. http://dx.doi.org/10.1289/ehp.1306613.

43. Papadopoulou, E., Sabaredzovic, A., Namork, E., Nygaard, U. C., Granum, B., \& Haug, L. S. (2016). Exposure of Norwegian toddlers to perfluoroalkyl substances (PFAS): the association with breastfeeding and maternal PFAS concentrations. Environment International, 94, 687-694. http://dx.doi.org/10.1016/j.envint.2016.07.006.

44. Pérez, F., Nadal, M., Navarro-Ortega, A., Fàbrega, F., Domingo, J. L., Barceló, D., \& Farré, M. (2013). Accumulation of perfluoroalkyl substances in human tissues. Environment International, 59, 354-362. http://dx.doi.org/10.1016/j.envint.2013.06.004.

45. Pitter, G., Da Re, F., Canova, C., Barbieri, G., Zare Jeddi, M., Daprà, F., ... \& Russo, F. (2020). Serum levels of Perfluoroalkyl substances (PFAS) in adolescents and young adults exposed to contaminated drinking water in the Veneto region, Italy: A Cross-Sectional Study Based on a Health Surveillance Program. Environmental health perspectives, 128(2), 027007. http://dx.doi.org/10.1289/EHP5337.

46. Preston, E. V., Rifas-Shiman, S. L., Hivert, M. F., Zota, A. R., Sagiv, S. K., Calafat, A. M., ... \& James-Todd, T. (2020). Associations of perand polyfluoroalkyl substances (PFAS) with glucose tolerance during pregnancy in Project Viva. The Journal of Clinical Endocrinology \& Metabolism, 105(8), e2864-e2876. http://dx.doi.org/10.1210/clinem/dgaa328.

47. R Core Team (2021). R: A language and environment for statistical computing. R Foundation for Statistical Computing, Vienna, Austria. URL https://www.R-project.org/.

48. Sapolsky, R. M., Romero, L. M., \& Munck, A. U. (2000). How do glucocorticoids influence stress responses? Integrating permissive, suppressive, stimulatory, and preparative actions. Endocrine reviews, 21(1), 55-89. http://dx.doi.org/10.1210/edrv.21.1.0389.

49. Shankar, A., Xiao, J., \& Ducatman, A. (2012). Perfluorooctanoic acid and cardiovascular disease in US adults. Archives of Internal Medicine, 172(18), 1397-1403. http://dx.doi.org/10.1001/archinternmed.2012.3393.

50. Signorino, G. (2012). Proximity and risk perception. Comparing risk perception 'profiles' in two petrochemical areas of Sicily (Augusta and Milazzo). Journal of Risk Research, 15(10), 1223-1243. http://dx.doi.org/10.1080/13669877.2012.670129.

51. Steenland, K., Fletcher, T., Stein, C. R., Bartell, S. M., Darrow, L., Lopez-Espinosa, M. J., ... \& Savitz, D. A. (2020). Evolution of evidence on PFOA and health following the assessments of the C8 Science Panel. Environment International, 145, 106125. http://dx.doi.org/10.1016/j.envint.2020.106125

52. Steenland, K., \& Winquist, A. (2021). PFAS and cancer, a scoping review of the epidemiologic evidence. Environmental Research, 194, 110690. http://dx.doi.org/10.1016/j.envres.2020.110690.

53. Stojanovich, L. (2010). Stress and autoimmunity. Autoimmunity reviews, 9(5), A271-A276.

http://dx.doi.org/10.1016/j.autrev.2009.11.014.

54. Sunderland, E. M., Hu, X. C., Dassuncao, C., Tokranov, A. K., Wagner, C. C., \& Allen, J. G. (2019). A review of the pathways of human exposure to poly-and perfluoroalkyl substances (PFASs) and present understanding of health effects. Journal of Exposure Science \& Environmental Epidemiology, 29(2), 131-147. http://dx.doi.org/10.1038/s41370-018-0094-1. 
55. Stein, C. R., Savitz, D. A., Elston, B., Thorpe, P. G., \& Gilboa, S. M. (2014). Perfluorooctanoate exposure and major birth defects. Reproductive Toxicology, 47, 15-20. http://dx.doi.org/10.1016/j.reprotox.2014.04.006.

56. Tian, Y., Zhou, Y., Miao, M., Wang, Z., Yuan, W., Liu, X., ... \& Liang, H. (2018). Determinants of plasma concentrations of perfluoroalkyl and polyfluoroalkyl substances in pregnant women from a birth cohort in Shanghai, China. Environment International, 119, $165-173$. http://dx.doi.org/10.1016/j.envint.2018.06.015.

57. Tsai, M. S., Chang, S. H., Kuo, W. H., Kuo, C. H., Li, S. Y., Wang, M. Y., ... \& Chen, P. C. (2020). A case-control study of perfluoroalkyl substances and the risk of breast cancer in Taiwanese women. Environment International, 142, 105850. http://dx.doi.org/10.1016/j.envint.2020.105850.

58. Van Buuren, S. (2011). Multiple imputation of multilevel data (pp. 181-204). Routledge. http://dx.doi.org/10.4324/9780203848852.ch10.

59. Viklund, M. J. (2003). Trust and risk perception in western Europe: A cross-national study. Risk Analysis: An International Journal, 23(4), 727-738. http://dx.doi.org/10.1111/1539-6924.00351.

60. Wickham, G. M., \& Shriver, T. E. (2021). Emerging contaminants, coerced ignorance and environmental health concerns: The case of per-and polyfluoroalkyl substances (PFAS). Sociology of Health \& IIIness. 43, 764. http://dx.doi.org/10.1111/1467-9566.13253.

61. World Health Organization (WHO), 55th World Health Assembly. Infant and young child nutrition. World Health Organization, 2002 (WHA55.25). http://apps.who.int/gb/archive/pdf_files/WHA55/ewha5525.pdf (last accessed on Jan 19th, 2022).

62. Zimet, G. D., Dahlem, N. W., Zimet, S. G., \& Farley, G. K. (1988). The multidimensional scale of perceived social support. Journal of personality assessment, 52(1), 30-41. http://dx.doi.org/10.1207/s15327752jpa5201_2.

\section{Figures}

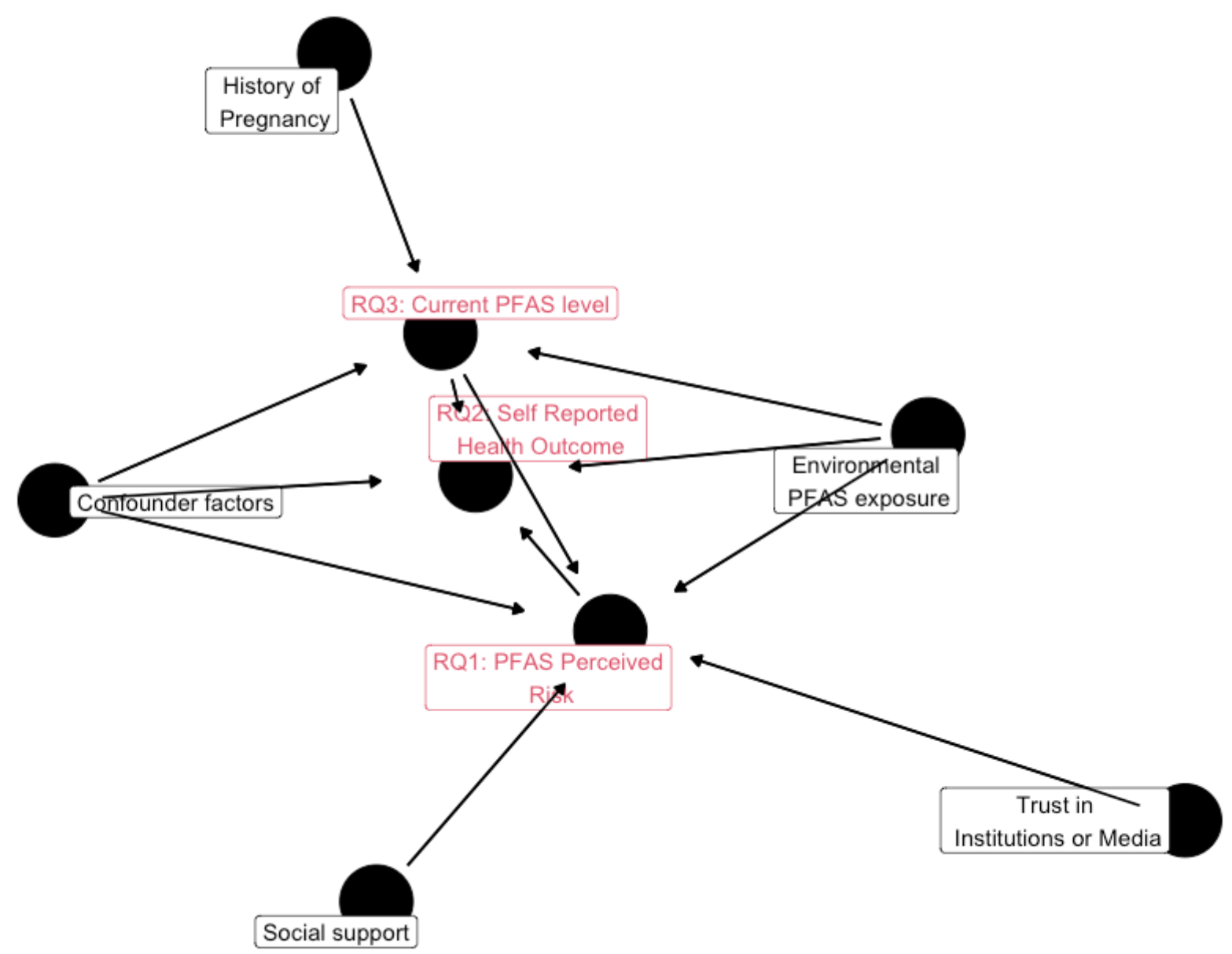

Figure 1 
Directed Acyclic Graph among study variables. In red the dependent variables investigated in each research question.

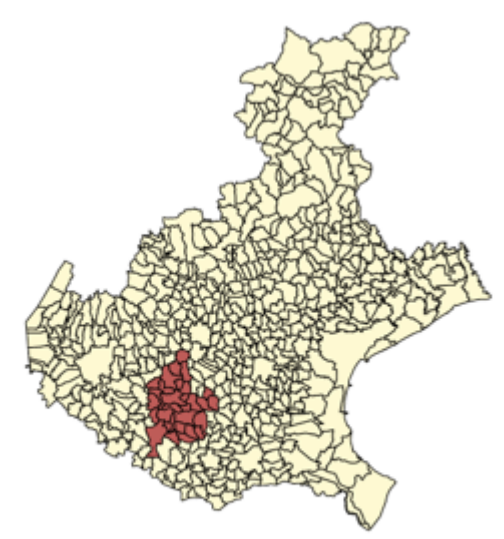

(a)
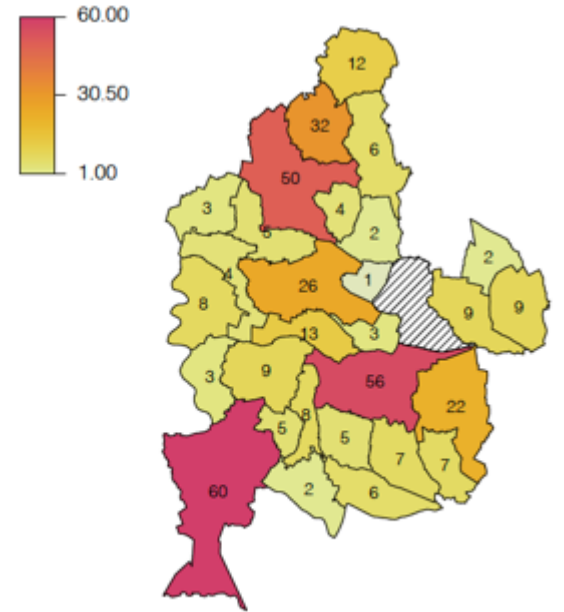

(c)

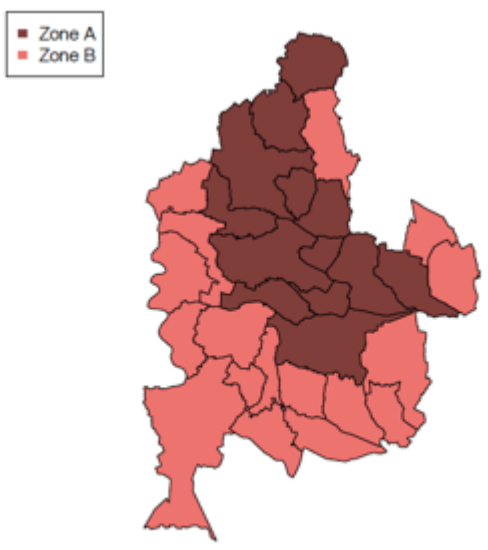

(b)
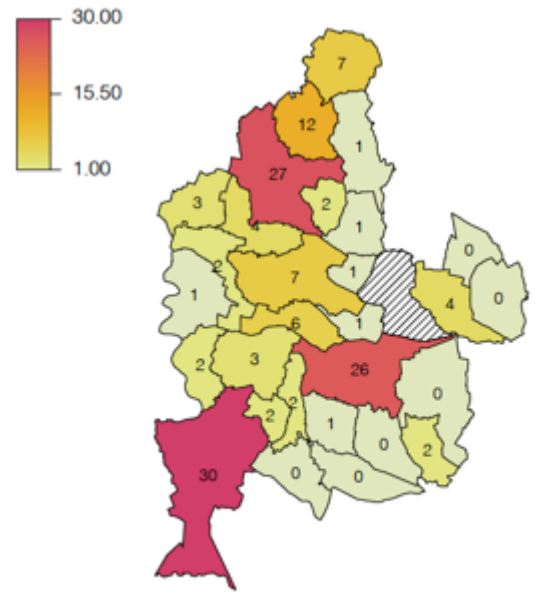

(d

\section{Figure 2}

(a) Red Zone in the Veneto Region, (b) subdivision of the Red Zone to Zone A and Zone B, (c and d) the number of participants and those with PFAS measurement for each municipality, respectively. 
Correlation between PFAS

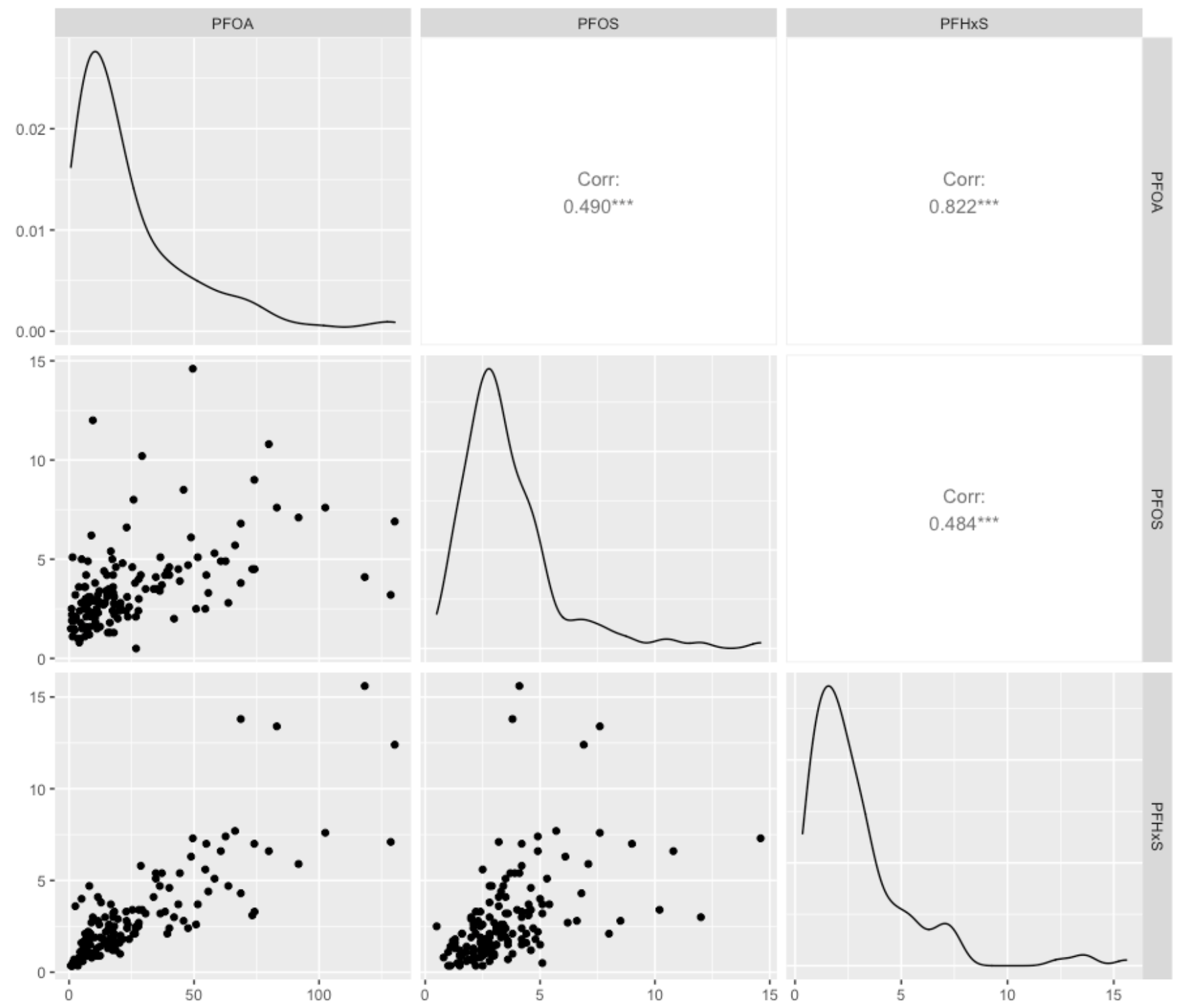

Figure 3

Pearson's correlation for the PFOA, PFOS, and PFHxS concentrations. 

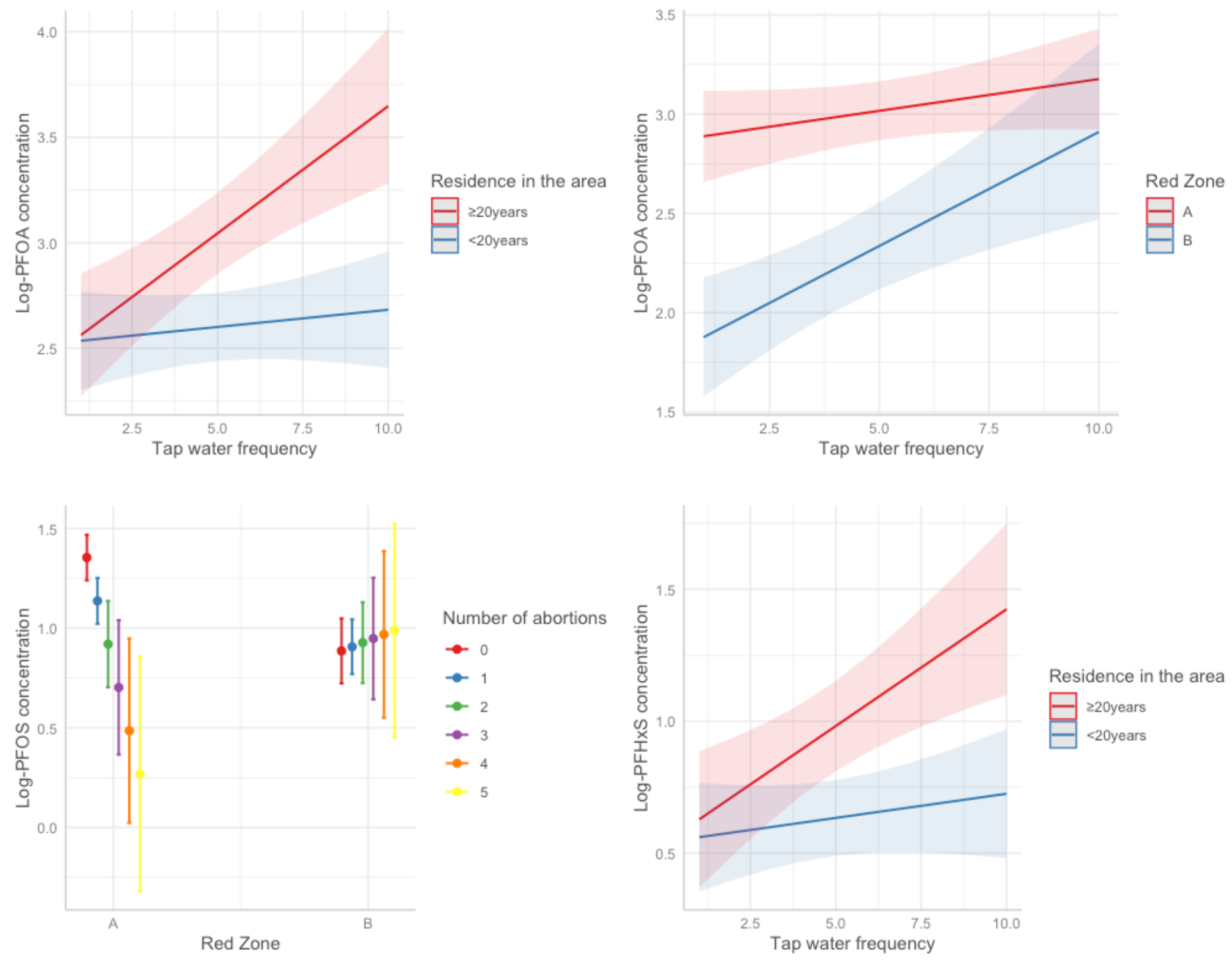

Figure 4

The predicted log-PFAS values, based on the interactions between variables in the log-PFAS regression models.

\section{Supplementary Files}

This is a list of supplementary files associated with this preprint. Click to download.

- Supplementarymaterial.docx 